Research Journal of Biological Sciences 7 (4): 152-158, 2012

ISSN: $1815-8846$

(C) Medwell Journals, 2012

\title{
Radiopacity of Various Dental Biomaterials
}

\author{
Hassan Torabzadeh, Sarah Aslanzadeh and Seed Asgary \\ Iranian Center for Endodontic Research, \\ Shahid Beheshti University of Medical Sciences, Evin, Tehran, Iran
}

\begin{abstract}
This study aims to assess the radiopacity of various dental biomaterials such as pulp-cappings (Life/Dycal), ZOE bases (Zonalin KemDent/Kimia), root canal sealers (AH26/ZOE), gutta-perchas (Gapadent/Spident/Meta Biomed/Suisse) and MTAs (ProRoot/Root/Angelus) along with Calcium-Enriched Mixture (CEM) cement. Five circular specimens ( $1 \mathrm{~mm}$ in thickness $/ 5 \mathrm{~mm}$ in diameter) were prepared from each material; five teeth were sliced horizontally with $1 \mathrm{~mm}$ thickness as well. Radiographic images of specimens were taken and recorded using digital radiography along with the graduated aluminum step-wedge. The x-ray unit was set at $65 \mathrm{kVp}, 8 \mathrm{~mA}, 18.5$ pulse $\mathrm{sec}^{-1}$ and $0.12 \mathrm{sec}$ exposure time and focus-film distance of $32 \mathrm{~cm}$. Radiographs were imported to Digora software to compare radiographic density of the materials, dentin and aluminum step-wedge thicknesses. Data were exported to SPSS to be analyzed using ANOVA and Tukey test. The radiopacity of dentin was measured $1.027 \mathrm{mmAl}$. Life and Dycal showed the radiopacity of 2.906 and $2.254 \mathrm{mmAl}$, respectively ( $<<0.05$ ). KemDent demonstrated higher radiopacity than Kimia (7.009 vs. $8.030 \mathrm{mmAl})$ $(\mathrm{p}<0.05)$. ZOE and AH26 as sealers exhibited the radiopacity of 5.891 and $8.612 \mathrm{mmAl}$, respectively $(\mathrm{p}<0.05)$. Gutta-perchas (Gapadnt $<$ Spident $<$ Meta Biomed $<$ Suisse) showed a radiopacity from 7.051-8.051 mmAl. Radiopacity of MTAs could be ranked as follows: [Angelus $=5.589 \mathrm{mmAl}$, Root $=5.519 \mathrm{mmAl}(\mathrm{p}>0.05)$ ] and ProRoot $=5.009 \mathrm{mmAl}(\mathrm{p}<0.05)$. CEM cement demonstrated the radiopacity of $2.227 \mathrm{mmAl}$. All biomaterials tested had radiopacity value of at least twice of the dentin. All brands of gutta-percha/sealers met and even exceeded the minimum radiopacity of ISO No. $9877 / 9876$.
\end{abstract}

Key words: Calcium enriched mixture, endodontic biomaterial, mineral trioxide aggregate, radiology, radiopacity, step-wedge

\section{INTRODUCTION}

Dental/endodontic materials such as root fillings, root-end fillings, root canal sealers, pulp cappings and liner/base materials should have adequate radiopacity to be easily distinguished by ISO 4049 (1988), ISO 6876 (2001), ISO 6877 (2006) and Gu and Rasimick (2006). In 1979, presented a standard measure to compare the radiopacity of different materials called aluminum stepwedge. In this system, the visual radiographic density of the material is measured and mentioned as the equivalent thickness of aluminum (mmAl) (Eliasson and Haasken, 1979). Assessment of dental materials in a clinical situation may become challenging due to both the thickness of adjacent teeth and osseous structures as well as mass of the material (Baksi Akdeniz and Eyuboglu, 2007).

Gutta-percha is the most commonly used material for root canal obturation (Aminzadeh et al., 2006). It contains zinc oxide and barium sulfate which contribute to its radiopacity (Katz and Kaffe, 1990). According to the
International Organization for Standardization (ISO) radiopacity of obturation cones should be $>3 \mathrm{mmAl}$ (ISO 6877, 2006). Reported the average radiopacity of gutta-percha points around $7.4 \mathrm{mmAl}$ (Katz and Kaffe, 1990).

As stated in the ISO 6876 (2001), radiopacity of the endodontic sealers should also be $\geq 3 \mathrm{mmAl}$. According to a more radiopaque sealer than gutta-percha cone seems better in order to increase the overall radiopacity of the root canal filling (Baksi Akdeniz and Eyuboglu, 2007). However, an excessively opaque sealer may mask defects in the gutta-percha filling (Gambarini and Testarelli, 2006). Calcium Hydroxide $(\mathrm{CH})$ is the traditional pulp capping agent. By producing alkaline $\mathrm{pH}, \mathrm{CH}$ affects remineralization of surrounding dentin when placed very close to the dental pulp. Ideally, pulp-capping materials should present adequate radiopacity to be differentiated from:

$$
\begin{aligned}
& \text { mmAl equivalent }=\text { Radiopacity of sample } \mathrm{x} \\
& \frac{\text { Closest Al thickness of step - wedge }}{\text { Radiopacity of Alstep -wedge }}
\end{aligned}
$$

Corresponding Author: Sarah Aslanzadeh, Iranian Center for Endodontic Research, Shahid Beheshti University of Medical Sciences, Evin, Tehran, Iran 
the adjacent dentin (Tam and Pulver, 1989). However, CH is used in a small quantity which makes the radiographic differentiation somehow difficult.

Zinc Oxide Eugenol ( $\mathrm{ZOE}$ ) is a common constituent of the cavity base, temporary fillings, liners and sealers. ZOE consists of grains of zinc oxide embedded in a zinc eugenolate matrix. These components are held together by van der Waals forces and particle interlocking so the material is mechanically weak. On the other hand, a large number of studies emphasize the advantageous biological properties of ZOE (Markowitz et al., 1992). In order to distinguish caries adjacent to the restorations and the dental structures, this material also should be sufficiently radiopaque. Mineral Trioxide Aggregate (MTA) is a water-based endodontic material which due to excellent biological properties, low solubility and marginal adaptation has been widely used by clinicians for the past decade (Parirokh and Torabinejad, 2010a, b; Torabinejad and Parirokh, 2010). MTA is a type I Portland cement radiopacified by bismuth oxide (Asgary et al., 2009a).

It is produced as either a white or grey prototype which are chemically different (Asgary and Parirokh, 2005). Studies report that PC and MTA have similar constituent elements except for the bismuth oxide in MTA (Estrela and Bammann, 2000; Funteas and Wallace, 2003; Asgary and Parirokh, 2004). Grey MTA is reported to have a radiopacity of $5.34 \mathrm{mmAl}$ (Danesh and Dammaschke, 2006). The prototype used by
Torabinejad et al. (1995) has a radiopacity of $7.17 \mathrm{mmAl}$. MTA has a lower radiopacity compared to Super-EBA, IRM, gutta-percha and Amalgam (Danesh and Dammaschke, 2006).

A novel endodontic biomaterial, Calcium Enriched Mixture (CEM) cement has recently been introduced with satisfactory clinical properties; the predominant elements in the CEM are calcium, sulfur, phosphorus and silicon (Asgary et al., 2008). Decreased setting time, higher flow ability, higher antimicrobial effect, less film thickness compared to MTA and ability to form hydroxyl apatite crystals with endogenous ionic origin are the advantages of this cement (Asgary et al., 2008, 2009b). Different studies have compared the radiopacity of various endodontic materials.

However to the best of the knowledge, CEM radiopacity has not been considered in previous studies. Thus, this in vitro study was designed to compare the radiopacity of different endodontic (bio) materials including the novel CEM cement.

\section{MATERIALS AND METHODS}

Preparation of moulds: FlatPerspex blocks, approximately $33 \mathrm{~cm}$ in length, $15 \mathrm{~cm}$ in width and $1 \mathrm{~mm}$ thick were used to form the moulds. Five holes, $5 \mathrm{~mm}$ in diameter each were drilled in each block as shown in Fig. 1.

Preparation of specimens: Dental/endodontic materials as shown in Table 1 were evaluated in terms of radiopacity

Table 1: Tested materials and their composition

\begin{tabular}{|c|c|c|}
\hline Products & Manufacture & Components \\
\hline \multirow[t]{4}{*}{ Gutta-percha } & Spident Co., Ltd, Korea & Gutta-percha \\
\hline & Meta Biomed Co., Ltd, Korea & Zinc oxide \\
\hline & Gapadent Co., Ltd, China & Barium sulfate \\
\hline & Dentaires S.A Vevey (Suisse) & Coloring agent \\
\hline \multirow[t]{2}{*}{ AH 26} & Dentsply, DeTray, GmbH, & Powder: $43 \%$ bismuth oxide, $37 \%$ calcium hy droxide, \\
\hline & Konstanz, Germany & $\begin{array}{l}\text { 14\%, hexamethyleneteramine and 5\% Titanium dioxide } \\
\text { Paste B: Bisphenol epoxy resin }\end{array}$ \\
\hline ZOE sealer & BP, Kemdent Works, Wiltshire, UK & Powder: zinc oxide $99.99 \%$, Liquid: eugenol \\
\hline Life & Kerr Corporation, Italy & $\begin{array}{l}\text { Base: Calcium hydroxide, zinc oxide, butyl benzene solfonamide } \\
\text { catalyst: barium sulfate, itanium dioxide, methyl salicylate }\end{array}$ \\
\hline \multirow[t]{4}{*}{ Dycal } & Dentsply, Espana y & Base paste: 1,3 Butyene glycol disalicilate, \\
\hline & Portugal Avda de Burgos, & zinc oxide, calcium phosphate,calcium \\
\hline & Madrid, & tungstate, iron oxide pigment. \\
\hline & Spain & $\begin{array}{l}\text { Catalyst paste: calcium hydroxide, N-ethyl- o/p_toluene } \\
\text { sulfonamide, zinc oxide, titanium dioxide, zinc stearate, iron oxide } \\
\text { pigments (dentine shade only) }\end{array}$ \\
\hline Zonalin Kimia & KimiaDent, Tehran, Iran & Zinc oxide: $99.35 \%$ \\
\hline $28{\mathrm{~g} 10 \mathrm{~mL}^{-1}}^{-1}$ & & Zinc acetate: $0.65 \%$, eugenol: $99 \%$ \\
\hline Zonalin Kem-dent & Associated Dental Products Ltd, & Zinc acetate $0.2 \% \mathrm{ww}$ \\
\hline $25{\mathrm{~g} 12 \mathrm{~mL}^{-1}}^{-1}$ & purton, swindon & Zinc oxide BP $99.8 \%$ ww \\
\hline ProRoot MTA & Dentsply, Tulsa Dental, OK, USA & Portland cement (75\%), bismuth oxide ( $20 \%$ ) and gypsum ( $5 \%)$ \\
\hline Root MTA & Lotfi and Saghiri Research group, Iran & $\begin{array}{l}\text { Calcium silicate, calcium aluminate, calcium } \\
\text { aluminoferrite, Bismuth Oxide, calcium sulfate }\end{array}$ \\
\hline MTA & Angelus Industria De Produtos & Tricalcium silicate, dicalcium silicate, \\
\hline Angelus & $\begin{array}{l}\text { Odontologicos, Ltda., Londrina, } \\
\text { PR, Brazil }\end{array}$ & $\begin{array}{l}\text { tetracalcium aluminoferrite, tricalcium aluminate, } \\
\text { bismuth kxide ( } 80 \% \text { portland cement, } 20 \% \text { bismuth oxide) }\end{array}$ \\
\hline CEM cement & BoniquDent, Tehran, Iran & $\begin{array}{l}\text { Calcium silicate, calcium phosphate, calcium } \\
\text { oxide, calcium salts, barium sulfate and zirconia }\end{array}$ \\
\hline
\end{tabular}


along with dentin. Five samples of each material were prepared using the mould described before. All materials were handled according to the manufacturers' instruction. The materials were mixed and used to fill to a slight excess, the mould which was resting on a Mylar strip supported by a glass plate (a glass microscope slide). Another Mylar strip was placed on top of the mould, followed by another glass plate which facilitated manual compression thus ensuring that excess material was displaced and the specimen had perfectly flat surface. Gutta-percha cones were warmed in $60^{\circ} \mathrm{C}$ water and were adapted into the holes. Excess gutta-percha was removed from the opining of the holes with a hot scalpel. Specimens with voids, bubbles or cracks were discarded and replaced. Each mould was incubated at $37^{\circ} \mathrm{C}$. Moreover, five freshly extracted human molar teeth were cut horizontally into 5 disks ( $1 \mathrm{~mm}$ thickness) using a microtome (Jung, Heidelberg, Germany). The disks were kept in distilled water during the study period.

The images of the specimens along with the aluminum step-wedge (made out of $99.5 \%$ pure aluminum from 1-8 $\mathrm{mm}$ in uniform steps of $1 \mathrm{~mm}$ each) were taken using Suni digital radiographic system sensors (Suni Medical Imaging Inc, San Jose, CA, USA) and a dental x-ray unit (Castellini, Bologna, Italy) operating at $65 \mathrm{kVp}, 8 \mathrm{~mA}$ and $0.12 \mathrm{sec}$ exposure time and focal length of $32 \mathrm{~cm}$.
Digitized images were imported to Digora for Windows software version 2.7 (Orion Corporation Soredex, Helsinki, Finland) where measure density tool was applied to identify equal-density areas in the radiographic images as shown in Fig. 2. This process allowed comparison between the radiographic density of the materials and the radiopacity of the different aluminum step-wedge thicknesses. Each specimen and each step measured for 10 times. The final density value of each material was analyzed by calculating the mean of fifty measurements (ten measurements $x$ five specimen). The following equation was used to convert the values into $\mathrm{mmAl}$ :

mmAl equivalent $=$ Radiopacity of sample $\mathrm{x}$

Closest Al thickness of step - wedge

Radiopacity of Alstep - wedge

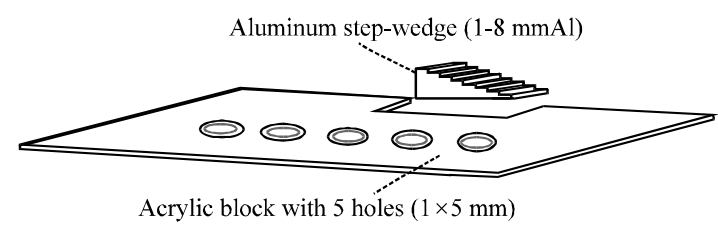

Fig. 1: Aluminum step-wedge and mould with five holes for the filling materials

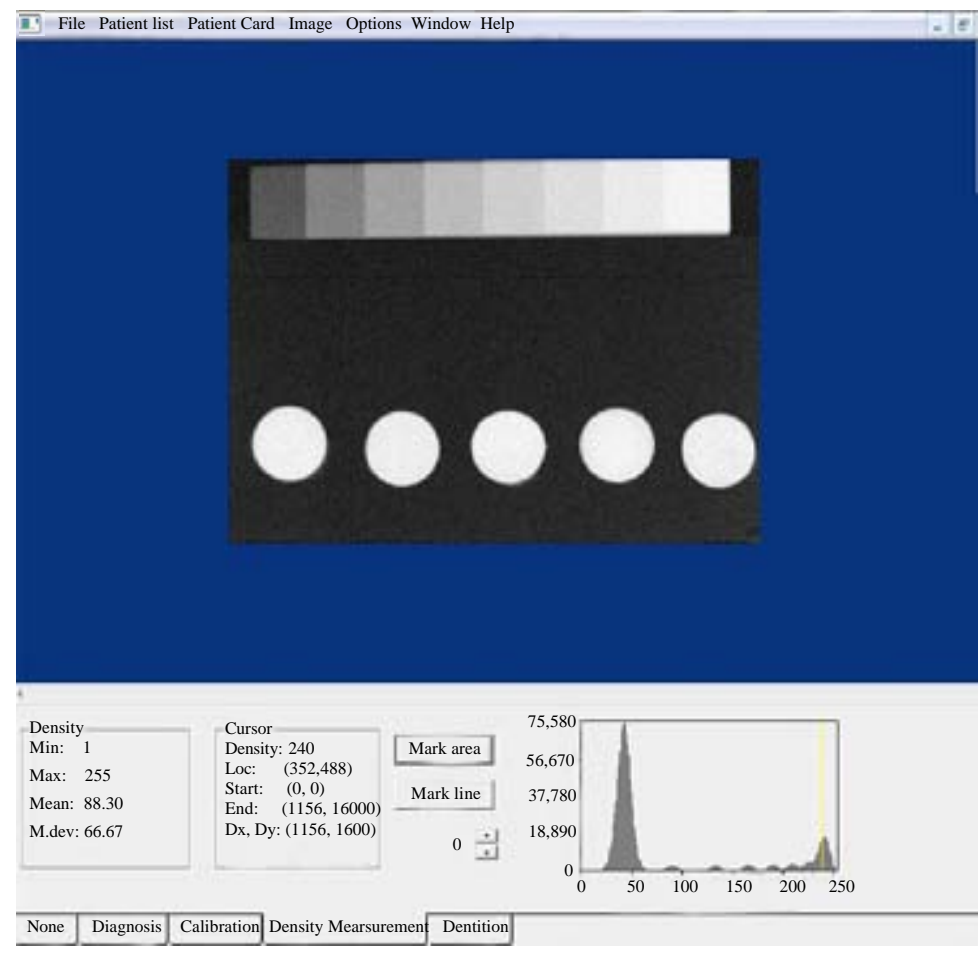

Fig. 2: Computer screen shows the radiopacity measurement by Digora software 
This equation established the equivalence of each material's radiopacity to a particular thickness of the aluminum step-wedge, expressed in $\mathrm{mm}$.

Statistical analysis was performed using SPSS (the Statistical Package for Social Sciences). Shapiro-Wilk test was used to assess normality of the distribution of the continuous data. The differences among materials were evaluated using one-way ANOVA. For multiple comparisons Tukey HSD method was used. $\mathrm{p}<0.05$ were considered as statistically significant.

\section{RESULTS AND DISCUSSION}

The mean radiographic density values of all endodontic materials used in this study along with dentin, in mmAl are shown in Table 2. Dentin showed the lowest mean value of radiopacity $(1.027 \mathrm{mmAl})$. All gutta-perchas and sealers showed the radiopacity of $>3 \mathrm{mmAl}$ which is the minimum recommended by ISO standards $9877 / 9876$ $(\mathrm{p}<0.05)$. Pulp-capping mterials, ZOE bases, MTAs and CEM cement all demonstrated significantly more radiopacity than dentin $(\mathrm{p}<0.05$ ) (Fig. 3 ). According to Tukey test, there was statistically significant difference among specific experimental groups showed in Table 2 with English alphabet letters. Graph of radiopacity density versus step-height in step-wedge is plotted in Fig. 4.

In this study, digital radiography in conjunction with Digora software were used to evaluate the radiopacity of various dental materials. This method was different in comparison with some previous studies (Beyer-Olsen and Orstavik, 1981; Gorduysus and Avcu, 2009) which used conversional radiography. Total degree of darkening of an exposed film is referred to as radiographic density. However in conventional radiography an unexposed film also shows some density owing to the base and added tint as well as development of unexposed silver halide crystals. This is called gross fog which has an optical density of 0.2-0.3 (White and Pharoah, 2004). It clearly shows a significant impact on the overall radiopacity of the materials shown on the film. Furthermore, conventional methods for analyzing the radiopacity of the materials in relation to the optical density needs more

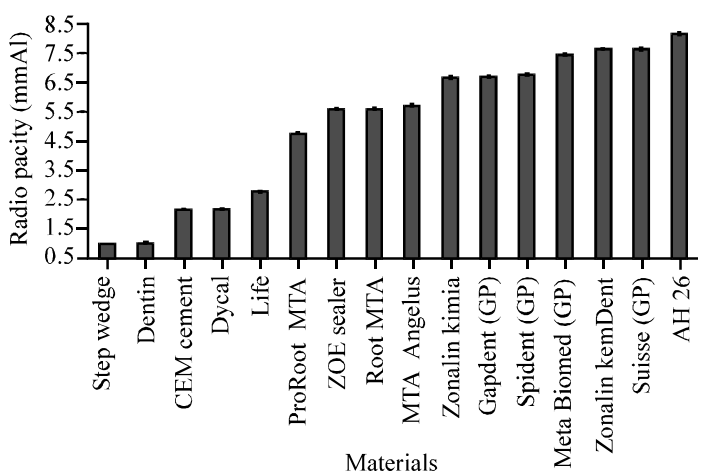

Fig. 3: Radiopacity of materials in comparison with dentin (1 mmAl)

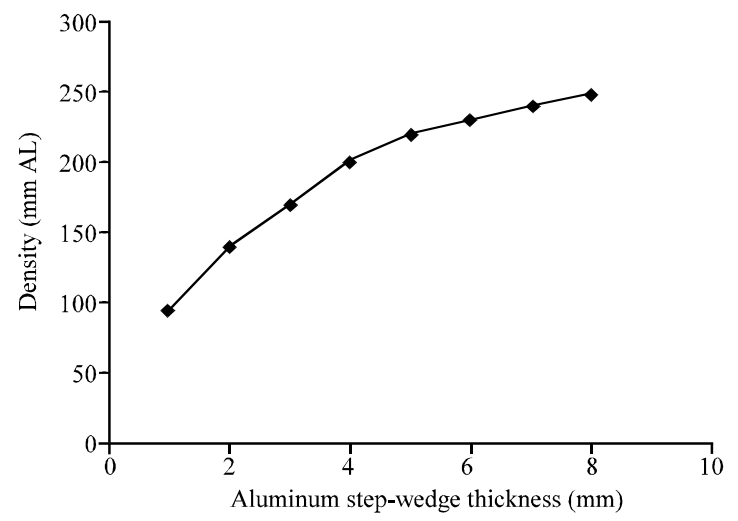

Fig. 4: Calibration of aluminum step-wedge

Table 2: One way ANOVA test results

\begin{tabular}{|c|c|c|c|c|c|c|}
\hline \multirow[b]{2}{*}{ Materials } & \multirow[b]{2}{*}{ Types } & \multirow[b]{2}{*}{ Mean \pm SE } & \multicolumn{2}{|c|}{$95 \%$ Confidence Interval } & \multirow[b]{2}{*}{ Min. } & \multirow[b]{2}{*}{ Max. } \\
\hline & & & Lower bound & Upper bound & & \\
\hline Dentin & & $1.020 \pm 0.002^{\mathrm{a}}$ & 1.020 & 1.034 & 1.023 & 1.037 \\
\hline \multirow{4}{*}{ Gutta-perchas } & Gapadent & $7.051 \pm 0.021^{b}$ & 6.991 & 7.110 & 7.000 & 7.130 \\
\hline & Spident & $7.095 \pm 0.023^{b}$ & 7.028 & 7.161 & 7.002 & 7.137 \\
\hline & Meta Biomed & $7.844 \pm 0.032^{c}$ & 7.753 & 7.935 & 7.726 & 7.916 \\
\hline & Suisse & $8.051 \pm 0.050^{d}$ & 7.911 & 8.191 & 7.856 & 8.127 \\
\hline \multirow[t]{2}{*}{ Root canal sealers } & $\mathrm{ZOE}$ & $5.891 \pm 0.013^{\mathrm{d}}$ & 5.854 & 5.927 & 5.857 & 5.928 \\
\hline & AH26 & $8.612 \pm 0.027^{f}$ & 8.536 & 8.688 & 8.537 & 8.691 \\
\hline \multirow[t]{2}{*}{ Pulp cappings } & Dycal & $2.254 \pm 0.009^{g}$ & 2.229 & 2.280 & 2.234 & 2.284 \\
\hline & Life & $2.906 \pm 0.020^{\mathrm{h}}$ & 2.849 & 2.964 & 2.838 & 2.951 \\
\hline \multirow[t]{2}{*}{ ZOE bases } & Kimia & $7.009 \pm 0.048^{b}$ & 6.873 & 7.145 & 6.896 & 7.169 \\
\hline & Kemdent & $8.030 \pm 0.021^{\mathrm{d}}$ & 7.970 & 8.090 & 7.964 & 8.100 \\
\hline Mineral & ProRoot MTA & $5.009 \pm 0.006^{i}$ & 4.991 & 5.028 & 4.993 & 5.026 \\
\hline Trioxide & Root MTA & $5.910 \pm 0.033^{\mathrm{e}}$ & 5.822 & 6.007 & 5.849 & 6.023 \\
\hline Aggregates & Angelus MTA & $5.987 \pm 0.027^{\circ}$ & 5.912 & 6.063 & 5.899 & 6.064 \\
\hline Calcium enriched mixture & & $2.227 \pm 0.023^{\mathrm{g}}$ & 2.163 & 2.292 & 2.189 & 2.300 \\
\hline
\end{tabular}

Different letters indicate a statistically significant difference (Tukey-Kramer test; $p<0.05$ ) 
expensive equipment compared to digital radiography. Considering this and also some other disadvantages of conventional method in point of variability in the quality of the radiographs, loss of information or incorrect differentiation of shades by naked eye this study used digital radiography with Digora software. This software gives the opportunity of direct reading of digital $\mathrm{x}$-ray and comparing the material and step-wedge together. In this study 10 measurements were collected from each specimen in this study instead of 3 or 5 measurements (Bortoluzzi and Guerreiro-Tanomaru, 2009). In addition, the distance from focal point to the object was fixed at $32 \mathrm{~cm}$. It is worth noting that the best results were obtained when a long-cone paralleling technique and a focal length of at least $30 \mathrm{~cm}$ were used (Aken, 1969).

Katz and Kaffe (1990) compared the radiopacity of different brands of gutta-percha by using step-wedge. In the same year, Curtis and Von Fraunhofer (1990) applied step-wedge in his study for evaluating the radiodensity of composite resins. In later studies, this method was used by many others with different standards for various goals (Parissis and Iakovidis, 1994; Tanomaru-Filho and Jorge, 2007). Meanwhile, it has been shown that using a stepwedge with an appropriate composition is an important milestone. ISO 6876 (2001) require aluminum of at least $98.0 \%$ purity with no $>1 \%$ iron and $0.1 \%$ copper. However, findings showed that alloys with $>0.05 \%$ copper should be excluded (Watts and McCabe, 1999). This study has followed the findings of Watts and McCabe (1999).

Radiographic density is influenced by thickness and density of the subject. As the thickness of the aluminum step-wedge increases, less photons pass through it to expose the film and the radiopacity increases (Fig. 4). As the step-wedge thickness increases pass a certain point ( $6 \mathrm{~mm}$ here), density shows diminishing returns and the density curve vs. step-wedge aluminum thickness starts to saturate. It means that after the 6th step the observed differentiation in radiopacity may become less noticeable.

Dentin radiopacity used as a control was uniform in all five specimens demonstrated almost $1 \mathrm{mmAl}$ radiopacity confirming previous studies (Beyer-Olsen and Orstavik, 1981; Devito and Ortega, 2004).

Ideal root canal sealers should present some certain physical and chemical properties. Also, one of the most important characteristic should be an acceptable degree of radiopacity to make them clearly visible on radiographs. Sealer's radiopacity has been an important factor in assessing the endodontic obturation (Baksi Akdeniz and Eyuboglu, 2007) but there is a controversy when comparing its radiopacity with accompanies gutta-percha. According to this study and other findings almost all commercial gutta-perchas met and even exceed the ISO 6877 (2006). Gutta-percha has been considered as the major root-canal filling material. However, sealers should just produce a hermitic seal in the filling. It has been reported that the radiopacity of sealers should exceed the radiopacity of gutta-percha in order to increase the overall radiopacity of the obturation (Baksi Akdeniz and Eyuboglu, 2007). However, sealers with the radiopacity more than that required by the ISO standards may cover the filling defects and lead to misdiagnosis.

Therefore, the radiopacity of the sealers should not be too high and a moderate degree of radiopacity is preferred. In other words, a very high radiopacity, similar to that of AH 26 does not provide the best condition for detecting voids in the fillings. So it is suggested that a maximum limitation for sealer's radiopacity to be determined by ISO.

Numerous studies have been suggested that dental materials including pulp cappings and ZOE bases need to show a radiopacity not less than dentin/enamel (Prevost and Forest, 1990; Shah and Chong, 1996). In this study, the mean radiopacity of pulp-cappings and ZOE bases showed a statistically higher radiopacity than that of dentin. Radiopacity of Life $(2.254 \mathrm{mmAl})$ and Dycal $(2.906 \mathrm{mmAl})$ were significantly higher than that reported by Devito and Ortega (2004). It may be related to the different research method which conducted. Unfortunately, there is not any recommendation by ISO standards for the radiopacity of these materials.

Shah and Chong (1996) claimed that the root-end filling materials with $<3 \mathrm{mmAl}$ radiopacity are indistinguishable. However, there is a challenge to achieve this level of radiopacity mainly due to small amounts of the material used. Considering that there is no ISO standard for the radiopacity of retro-filler materials, it is necessary to determine the minimum radiopacity required. In this study, all three kinds of MTA cements, e.g., Root, ProRoot and Angelus showed an acceptable amount of radiopacity $>3 \mathrm{mmAl}$.

Notable difference in the amount of Root MTA and MTA Angelus radiopacity was not detected. Moreover to the best of the knowledge, there is not any investigation about the radiopacity of Novel CEM cement which has been clinically used as root-end filling (Asgary et al., 2010), perforation repair (Samiee et al., 2010), pulpotomy agent (Malekafzali and Shekarchi, 2011; Asgary and Eghbal, 2012; Asgary et al., 2012; Nosrat and Seifi, 2012) and in regenerative endodontics (Nosrat and Seifi, 2011). Thus, the present study was conducted to evaluate radiopacity of this novel cement. Although ISO for retro-fillings is unavailable, the results revealed that the CEM cement has higher radiopacity than dentin. It is 


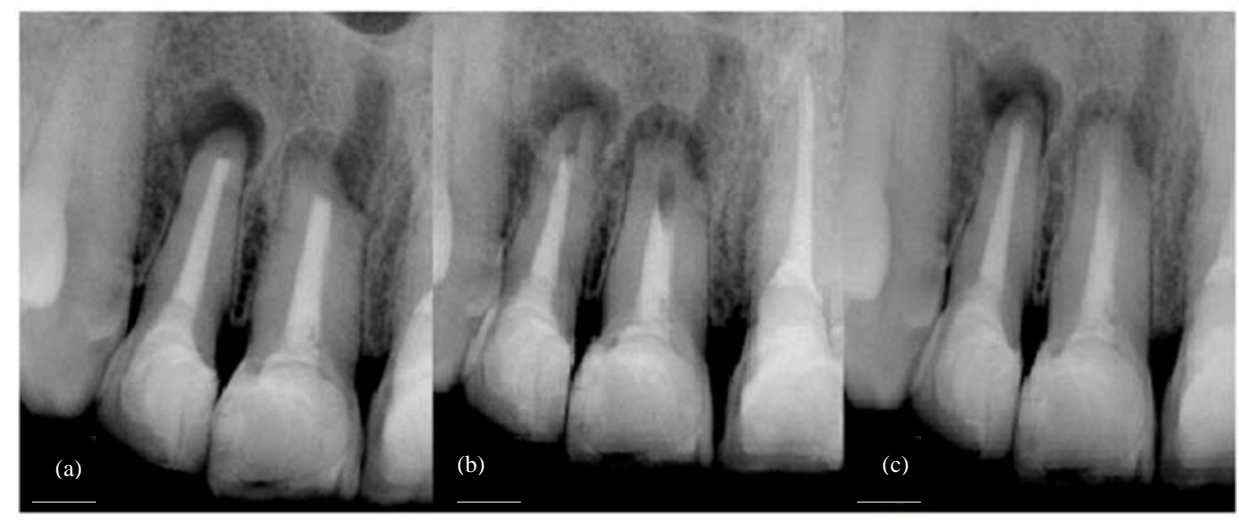

Fig. 5: a) Before periradicular surgery; b) After root-end cavity preparation; c) Immediate after root-end fillingwith CEM cement

worth noting that although radiopacity of CEM cement is much less than gutta-percha or root canal sealer but it seems that results may vary in clinical cases (Fig. 5) owing to the diameter of the dentin, overlying bone around teeth, the diameter of the cavity preparation (amount of the material) and other possible related issues.

\section{CONCLUSION}

Based on the results of this research, all of the sealers and gutta-perchas showed adequate radiopacity according to the ISO 6876/6877. However, it is suggested that this standard should be revised in order to recommend a maximum radiopacity. In addition, ISO for root-end filling materials, pulp-capping and ZOE bases are required. Provided that all of the materials had the radiopacity more than dentin $(1 \mathrm{mmAl})$, their density was considered acceptable.

\section{ACKNOWLEDGEMENTS}

This study has been conducted as a joint project by Iranian Center for Endodontic Research and Dental Research Center of Shahid Beheshti University of Medical Sciences (SBMUS), Tehran, Iran.

\section{REFERENCES}

Aken, J.V., 1969. Optimum conditions for intraoral roentgenograms. Oral Surg. Oral. Med. Oral. Pathol., 27: 475-491.

Aminzadeh, N., S. Azimi and M.H. Shenas, 2006. Component analysis of four commercial brands of Gutta-Percha. Iranian Endodontic J., 1: 48-52.
Asgary, S. and M. Parirokh, 2004. A comparative study of white mineral trioxide aggregate and white Portland cements using X-ray microanalysis. Aust. Endod. J., 30: 89-92.

Asgary, S. and M. Parirokh, 2005. Chemical differences between white and gray mineral trioxide aggregate. J. Endod., 31: 101-103.

Asgary, S., S. Shahabi, T. Jafarzadeh, S. Amini and S. Kheirieh, 2008. The properties of a new endodontic material. J. Endod., 34: 990-993.

Asgary, S., M.J. Eghbal, M. Parirokh and J. Ghoddusi, 2009a. Effect of two storage solutions on surface topography of two root-end fillings. Aust. Endodon. J., 35: 147-152.

Asgary, S., M.J. Eghbal, M. Parirokh, J. Ghoddusi, S. Kheirieh and F. Brink, 2009b. Comparison of mineral trioxide aggregate's composition with Portland cements and a new endodontic cement. J. Endod., 35: 243-250.

Asgary, S., M.J. Eghbal and S. Ehsani, 2010. Periradicular regeneration after endodontic surgery with Calcium-enriched mixture cement in dogs. J. Endod., 36: 837-841.

Asgary, S. and M. J. Eghbal, 2012. Treatment outcomes of pulpotomy in permanent molars with irreversible pulpitis using biomaterials: A multi-center randomized controlled trial. Acta Odontol. Scand. 10.3109/00016357.2011.654251.

Asgary, S., M.J. Eghbal, J. Ghoddusi and S. Yazdani, 2012. One-year results of vital pulp therapy in permanent molars with irreversible pulpitis: An ongoing multicenter, randomized, non-inferiority clinical trial. Clin. Oral. Investig. 10.1007/s00784-012-0712-6

Baksi Akdeniz, B.G. and T.F. Eyuboglu, 2007. The effect of three different sealers on the radiopacity of root fillings in simulated canals. Oral. Surg. Oral. Med. Oral. Pathol. Oral. Radiol. Endod., 103: 138-141. 
Beyer-Olsen, E.M. and D. Orstavik, 1981. Radiopacity of root canal sealers. Oral. Surg. Oral. Med. Oral. Pathol., 51: $320-328$.

Bortoluzzi, E.A. and J.M. Guerreiro-Tanomaru, 2009. Radiographic effect of different radiopacifiers on a potential retrograde filling material. Oral. Surg. Oral. Med. Oral. Pathol. Oral. Radiol. Endod., 108: 628-632.

Curtis, P.M., Jr. and J.A. Von Fraunhofer, 1990. The radiographic density of composite restorative resins. Oral. Surg. Oral. Med. Oral. Pathol., 70: 226-230.

Danesh, G. and T. Dammaschke, 2006. A comparative study of selected properties of ProRoot mineral trioxide aggregate and two Portland cements. Int. Endod. J., 39: 213-219.

Devito, K.L. and A.I. Ortega, 2004. Radiopacity of calcium hydroxide cement compared with human tooth structure. J. Appl. Oral. Sci., 12: 290-293.

Eliasson, S.T. and B. Haasken, 1979. Radiopacity of impression materials. Oral. Surg. Oral. Med. Oral. Pathol., 47: 485-491.

Estrela, C. and L.L. Bammann, 2000. Antimicrobial and chemical study of MTA, Portland cement, calcium hydroxide paste, Sealapex and Dycal. Braz Dent. J., 11: 3-9.

Funteas, U.R. and J.A. Wallace, 2003. A comparative analysis of mineral trioxide aggregate and portland cement. Aust Endod. J., 29: 43-44.

Gambarini, G. and L. Testarelli, 2006. Radiographic and rheological properties of a new endodontic sealer. Aust. Endod. J., 32: 31-34.

Gorduysus, M. and N. Avcu, 2009. Evaluation of the radiopacity of different root canal sealers. Oral. Surg. Oral. Med. Oral. Pathol. Oral. Radiol. Endod., 108: $135-140$.

Gu, S. and B.J. Rasimick, 2006. Radiopacity of dental materials using a digital X-ray system. Dent Mater, 22: $765-770$.

ISO 4049, 1988. Dentistry-resin-based filling materials. International Organization for Standardization, Geneva, Switzerland.

ISO 6876, 2001. Dentistry-root canal sealing materials. International Organization for Standardization, Geneva, Switzerland.

ISO 6877,2006 . Dentistry-root canal obturating points. International Organization for Standardization, Geneva, Switzerland.

Katz, A. and I. Kaffe, 1990. Densitometric measurement of radiopacity of Gutta-percha cones and root dentin. J. Endod., 16: 211-213.

Malekafzali, B. and F. Shekarchi, 2011. Treatment outcomes of pulpotomy in primary molars using two endodontic biomaterials. A 2-year randomised clinical trial. Eur. J. Paediatr. Dent., 12: 189-193.
Markowitz, K., M. Moynihan, M. Liu and S. Kim, 1992. Biologic properties of eugenol and zinc oxideeugenol: A clinically oriented review. Oral Surg. Oral Med. Oral Pathol., 73: 729-737.

Nosrat, A. and A. Seifi, 2011. Regenerative endodontic treatment (revascularization) for necrotic immature permanent molars: A review and report of two cases with a new biomaterial. J. Endod., 37: 562-567.

Nosrat, A. and A. Seifi, 2012. Pulpotomy in caries-exposed immature permanent molars using calcium-enriched mixture cement or mineral trioxide aggregate: A randomized clinical trial. Int. J. Paediatr. Dent, 10.1111/j.1365-263X.2012.01224.x

Parirokh, M. and M. Torabinejad, 2010a. Mineral trioxide aggregate: A comprehensive literature review--Part III: Clinical applications, drawbacks and mechanism of action. J. Endod., 36: 400-413.

Parirokh, M. and M. Torabinejad, 2010b. Mineral trioxide aggregate: A comprehensive literature review: Part I: Chemical, physical and antibacterial properties. J. Endod., 36: 16-27.

Parissis, N. and D. Iakovidis, 1994. Radiopacity of elastomeric impression materials. Aust. Dent. J., 39: $184-187$

Prevost, A.P. and D. Forest, 1990. Radiopacity of glass ionomer dental materials. Oral. Surg. Oral. Med. Oral. Pathol., 70: 231-235.

Samiee, M., M.J. Eghbal, M. Parirokh, F.M. Abbas and S. Asgary, 2010. Repair of furcal perforation using a new endodontic cement. Clin. Oral Investig., 14: 653-658

Shah, P.M. and B.S. Chong, 1996. Radiopacity of potential root-end filling materials. Oral. Surg. Oral. Med. Oral. Pathol. Oral. Radiol. Endod., 81: 476-479.

Tam, L.E. and E. Pulver, 1989. Physical properties of calcium hydroxide and glass-ionomer base and lining materials. Dent Mater, 5: 145-149.

Tanomaru-Filho, M. and E.G. Jorge, 2007. Radiopacity evaluation of new root canal filling materials by digitalization of images. J. Endod., 33: 249-251.

Torabinejad, M. and M. Parirokh, 2010. Mineral trioxide aggregate: A comprehensive literature review-Part II: Leakage and biocompatibility investigations. J. Endod., 36: 190-202.

Torabinejad, M., C.U. Hong, F. McDonald and T.R.P. Ford, 1995. Physical and chemical properties of a new root-end filling material. J. Endod., 21: 349-353.

Watts, D.C. and J.F. McCabe, 1999. Aluminium radiopacity standards for dentistry: An international survey. J. Dent., 27: 73-78.

White, S.C. and M.J. Pharoah, 2004. Oral Radiology: Principles and Interpretation. 5th Edn., Mosby, USA., ISBN: 9780323020015, pp: 57-59. 